Article

\title{
Taranto's Long Shadow? Cancer Mortality Is Higher for People Living Closer to One of the Most Polluted City of Italy
}

\author{
Roberto Cazzolla Gatti ${ }^{1, *(1)}$ and Alena Velichevskaya ${ }^{2}$ \\ 1 Department of Biological, Geological and Environmental Sciences, Alma Mater Studiorum-University of \\ Bologna, 40126 Bologna, Italy \\ 2 Biological Institute, Tomsk State University, 634050 Tomsk, Russia; alena.velichevskaya@gmail.com \\ * Correspondence: roberto.cazzollagatti@unibo.it
}

check for

updates

Citation: Cazzolla Gatti, R.;

Velichevskaya, A. Taranto's Long Shadow? Cancer Mortality Is Higher for People Living Closer to One of the Most Polluted City of Italy.

Sustainability 2022, 14, 2662. https:// doi.org/10.3390/su14052662

Academic Editors: Ezzat R. Marzouk, Amro Hassanein and Waleed

Hares Shetaya

Received: 17 January 2022

Accepted: 22 February 2022

Published: 24 February 2022

Publisher's Note: MDPI stays neutral with regard to jurisdictional claims in published maps and institutional affiliations.

Copyright: (C) 2022 by the authors. Licensee MDPI, Basel, Switzerland. This article is an open access article distributed under the terms and conditions of the Creative Commons Attribution (CC BY) license (https:// creativecommons.org/licenses/by/ $4.0 /)$.

\begin{abstract}
A national-scale study in Italy showed an incidence of cancer higher in the territories indicated as highly polluted compared to the regional average. One of them, the city of Taranto in Apulia (Italy), which is considered one of the most polluted cities in Europe, has numerous industrial activities that impact population health. We studied the epidemiological effects of a high level of pollution produced by the industrial area of Taranto in increasing the mortality rate for some specific cancer types in the city and towns of the two provinces located downwind. We analysed 10-year mortality rates for 15 major types of tumours reported among the residents of Taranto, of eight surrounding towns, randomly placed within an imaginary cone in the main wind direction from the vertex of the industrial zone of Taranto, and of the two related provinces (Bari and Taranto's metropolitan areas). Our results confirm our hypothesis that the mortality rate for some specific types of cancer is higher than the norm in the municipality of Taranto. We also found strong evidence that, for 12 out of 15 tumour types, mortality decreases with the distance of the other towns from Taranto's industrial site. However, we have reasons to believe that other local causes may be implicated in the excess of mortality in some specific municipalities besides the potential dispersal of pollutants from the industrial area of Taranto. The proximity to Taranto cannot, in fact, explain all the anomalies detected in some populations. It is likely that other site-specific sources of heavy pollution are playing a role in worsening the death toll of these towns and this must be taken into serious consideration by environmental policymakers and local authorities.
\end{abstract}

Keywords: cancer mortality; air pollution; long-distance dispersal; Taranto; industry

\section{Introduction}

Air pollution and, specifically, atmospheric particulate matter (i.e., also known as fine dust or PM) are catalogued among the confirmed carcinogens for humans (IARC 2013). Recent research and reviews of scientific studies on the subject determined that air pollution can cause lung cancer and increases the risk of bladder tumours [1-3]. One of the main sources of pollution is the industry, followed by urban traffic, agricultural emissions, heating, etc. [4]. A national-scale study in Italy showed an incidence of cancer (of various types) $9 \%$ higher in males and 7\% higher in females compared to the regional average in the territories indicated as highly polluted [5].

In the city of Taranto in Apulia (Italy), there are numerous and diverse anthropogenic impacts connected to the presence of industrial activities. The city of Taranto has great importance for the Italian economy and is home to a large industrial, commercial and military port, the arsenal of the Italian Navy and an important industrial centre with steel plants (including Ilva, the largest steel centre of Europe), petrochemical (ENI refineries), cement (Cementir) and shipbuilding [6].

Multiple environmental monitoring studies and campaigns of measurement of industrial emissions carried out in the Taranto area highlighted a widespread environmental 
pollution situation and the significant contribution of the industrial centre, in particular the steel plant and the petrochemical complex, as a source of pollutants of sanitary interest [7].

The population of Taranto, together with that of the other main Italian cities included in the list of highly polluted areas, has been the subject to several epidemiological and health impact studies that have documented the role of air pollution on the increase in short and long term effects, such as mortality and morbidity for tumours [8].

The presence of critical issues regarding the pathologies associated with the pollutants emitted by the factories in the industrial area of Taranto, confirmed by the local health agency [9], induced many institutions and organizations to claim the closure order of the factories in the territory. However, the industrial area has remained largely operative during the last decade. At the same time, the excess of tumour pathologies, with particular reference to lymphopoietic cancers, has kept a high death toll [10]. Another study to assess the exposure of Taranto citizens to dioxins and PCBs through the analysis of breast milk confirmed that, on average, the concentration of these substances in women residing in Taranto was $28 \%$ higher than those residing in the province and in line with what observed in other industrialized areas in Italy [11].

The effects of air pollution dispersal in increasing the cancer mortality rate of surrounding populations from the main industrial source (such as that of Taranto) have been, however, poorly explored [12] and mainly focused on "wind-days" [13]. Although it is well-known that air pollutants can disperse over long ranges, affecting also the locations that are far from the source and not only those in its extreme proximity, very few studies have investigated this issue and found contrasting results (see for instance [14,15]).

Here we hypothesize that the high level of air pollution (as a proxy of environmental contamination) emitted by the industrial area of Taranto increases the mortality rate for some specific cancer types in the city but also impacts the towns of the two provinces located downwind. To test our hypothesis, we analysed 10-year (2009-2018) mortality rates for 14 major types of tumours reported among the residents of Taranto, of 8 surrounding towns-randomly placed within an imaginary cone in the main wind direction from the vertex of the industrial zone of Taranto, and of the two provinces (Bari and Taranto) to which these municipalities belong to.

\section{Methods}

Considering that winter winds blowing in the Gulf of Taranto from N-NO disperse most of the atmospheric pollutants from the city of Taranto to the Ionian Sea, to analyse the potential epidemiological effects of air pollutants dispersion (as a proxy of environmental pollution) from a selected source (the industrial area of Taranto) to inhabited surrounding areas, in this study we considered the main direction and frequency of winds blowing towards the mainland [16]. These are spring and summer SO breezes and SE winds in autumn (see the inset of wind directions in Figure 1). On an annual basis, the direction $\mathrm{N}$ has the greatest persistence ( $75 \mathrm{~h}$ with 16 knots of average speed), followed by $\mathrm{S}$ direction ( $69 \mathrm{~h}$ with 13 knots of average speed) and E (66 h with 9 knots of average speed). The average direction of winds interesting for our analysis was S-SE. As study sites we, therefore, randomly selected eight municipalities, at different distances $(0-60 \mathrm{~km})$, within an imaginary cone of pollutants dispersion in direction S-SE from Taranto (as the vertex of the imaginary cone; Figure 1). We also included the city of Taranto as the 9th study site and the two provincial areas in the region (the Metropolitan Areas of Bari and Taranto) to which the nine studied municipalities belong.

Epidemiological data provided by the Italian National Institute of Statistics [17] of the resident population from 2009 to 2018 of the most recent ten-year period (available at the time of data collection) in Italy, for the provinces of Bari and Taranto and the territory of the nine municipalities above mentioned were collected for this study. Data on mortality causes divided by age groups $(0 ; 1-4 ; 5-9 ; 10-14 ; \ldots ; 95+)$ were collected at the national level (Italy). Mortality referred to all forms of cancer were extracted from the datasets. 
The analysis was carried out using the statistical software $\mathrm{R}$ [18] on datasets in csv format.

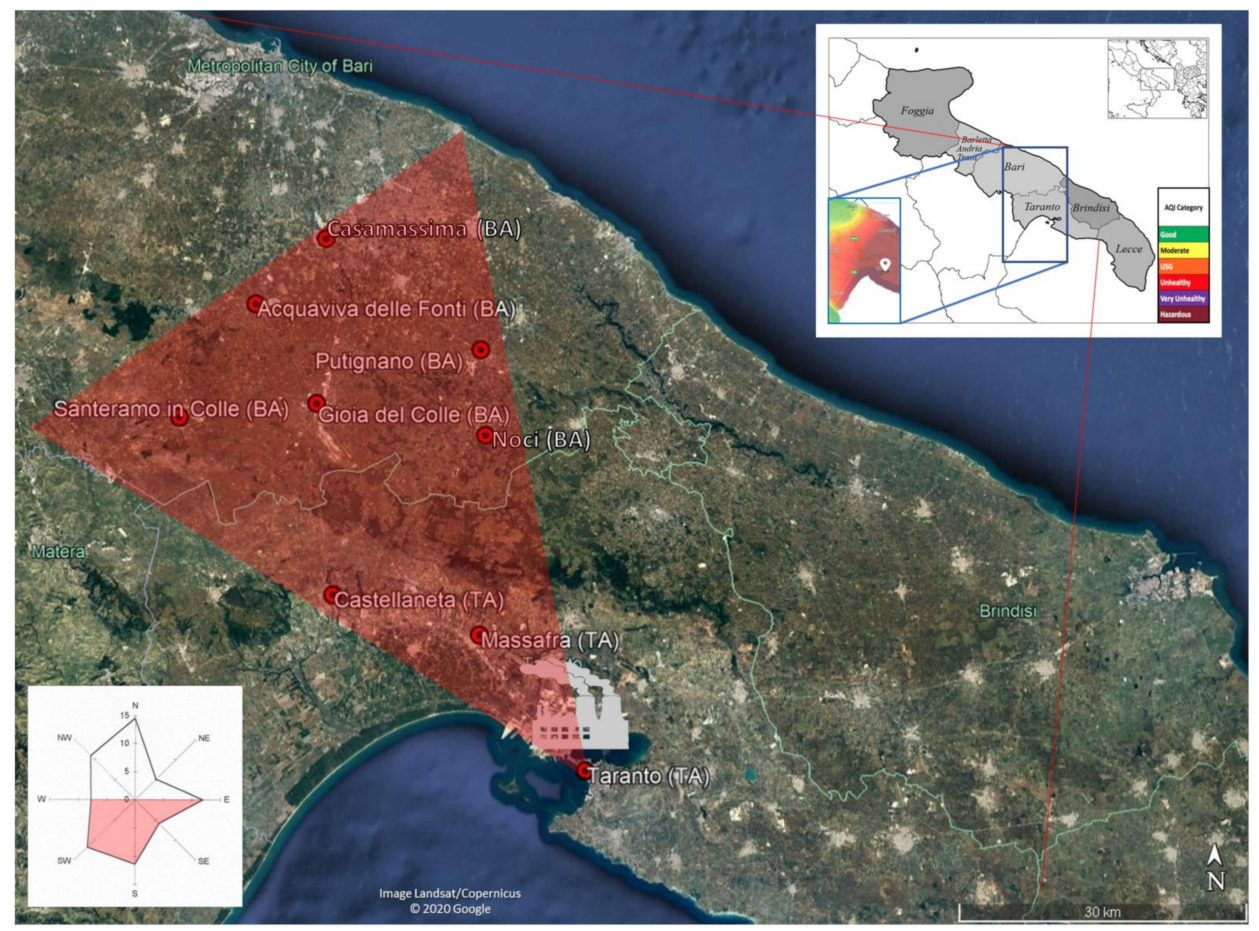

Figure 1. The location of the nine study sites in an imaginary cone of the wind directions towards the mainland. The lower-left inset shows the frequency of the wind direction and, highlighted in red, are those directed towards inhabited areas. The red imaginary cone on the map with the industrial area of Taranto as the dispersion vertex of pollutants was placed to randomly select eight municipalities, besides Taranto, in S-SE wind direction. The Provinces of Bari and Taranto, the two provinces in the region that include the nine studied municipalities, are shown in the upper-right inset with a representative heat map that shows the Air Quality Index (AQI; green: low pollution, brown: high pollution) in Taranto and surrounding areas in an average day as a proxy of environmental pollution. (Background satellite image Landsat/Copernicus Google 2020@).

To carry out a statistical comparison between the different resident populations, neutralizing the effects deriving from their different age structures, the results were further standardized through the use of the indirect method [19]. The indirect method, defined as the Standardized Mortality Rate (SMR), is based on the ratio between the deaths observed in a territory and those expected in the same. The expected deaths were calculated by applying the corresponding specific mortality ratios of the population assumed as standard (the national one in this analysis) to the average annual population by age classes of each territorial unit. The SMR, therefore, expresses the relationship between the deaths observed in a specific territory and the expected deaths if in the same territory there was the annual mortality, specific for age groups, of the population used as standard. The confidence intervals (C.I.) of the standardized mortality ratios were calculated at $95 \%$ using the Poisson model, providing an upper and lower bound. The 95\% C.I. lower bound was used as the reference to define the significance level of the excess mortality compared to the national standard. The SMR of the Provinces of Bari and Taranto was also considered for comparison among the SMR of the specific tumour categories of the nine municipalities.

Linear regression analysis and the estimation of the Pearson's correlation coefficient (r) was conducted for the 10-year mortality data between the SMR (lower 95\% C.I.) of each tumour type for each of the nine municipalities and their distance from the industrial site of Taranto (TA). 


\section{Results}

\section{Standardized Mortality Rate for All Tumour Types}

From the analysis of the standardized mortality rate (SMR) for all tumours (i.e., from all the causes of cancer death recorded throughout the national territory), between 2009 and 2018, mortality in the municipality of Taranto results above the national level for both rare and benign or with uncertain behaviour cancers, and higher than the rates of the provinces of Taranto and Bari, respectively. Although the 95\% C.I. lower bound of malignant and all tumours is close to the Italian standard value, it is above the rates of both provinces of Bari and Taranto (Figure 2).

No other municipalities show exceeding levels for these four general categories of tumours, except for Massafra (TA) that has a higher rate of mortality compared to the whole Province of Bari for all tumours and Noci (BA) that shows mortality for rare cancers that exceeds the national level and that of the province of Taranto (Figure 2).

From the analysis of the standardized mortality rate (SMR) of all the specific types of malignant tumours (i.e., all the causes of cancer reported at the national level) in the ten years 2009-2018, more details emerge (Figure 2).

Mortality for liver and intrahepatic bile duct tumours among the residents of the municipalities of Taranto (TA), Massafra (TA) and Gioia del Colle (BA) is significantly higher than the national average and, in the case of Taranto and Massafra, also than the rate of the whole Province of Taranto The municipality of Massafra (TA) shows mortality for colon, rectus and anus tumours significantly higher than the both provinces' levels. Taranto (TA) is the only studies municipality that significantly exceeds the mortality rate for pancreatic cancer of both provinces.

Mortality for trachea, bronchi, and lung tumours is significantly higher than both provincial rates for Taranto (TA) and exceeds the rare of the province of Bari in the town of Casamassima (BA). It is worth noticing that the SMR at lower $95 \%$ C.I. is very slightly below the national standard $(=1)$ with the average exceeding it. Skin melanoma has an SMR higher than the national and provincial levels in the municipality of Casamassima (BA) and exceeds the rate of the province of Taranto in the municipality of Putignano (BA). Only Taranto (TA) shows an excess of mortality for breast tumours compared to that of both provinces of Bari and Taranto.

The municipality of Castellaneta (TA) shows higher than national and provincial rates of mortality for tumours in the other parts of the uterus.

Gioia del Colle (BA) shows a significant excess of mortality for prostatic cancer compared to both national and provincial levels, whereas the rates of Acquaviva delle Fonti (BA) and Castellaneta (TA) are above the national standard and the level of the province of Taranto. Mortality for bladder cancer is higher than the national standard only among the residents of Taranto (TA).

Finally, we found that the municipality of Taranto (TA), Massafra (TA), and Gioia del Colle (BA) have a mortality rate for Hodgkin's disease and lymphomas higher than the level of the whole province of Taranto. The mortality in Massafra (TA) was also significantly above the rate of the whole province of Bari. Only Acquaviva delle Fonti (BA), shows a mortality rate for leukaemia exceeding the national and both provincial levels.

In the study period 2009-2018, there have been no recorded cases of significant cancer mortality rates in all municipalities for the lips, oral cavity, and pharynx, oesophagus, larynx, stomach, ovary, cervix, kidney, brain and central nervous system, other tumours of lymphatic/haematopoietic tissue, and thyroid gland (not displayed in Figure 2). 
Standardized Mortality Rate $\pm 95 \%$ C.I.

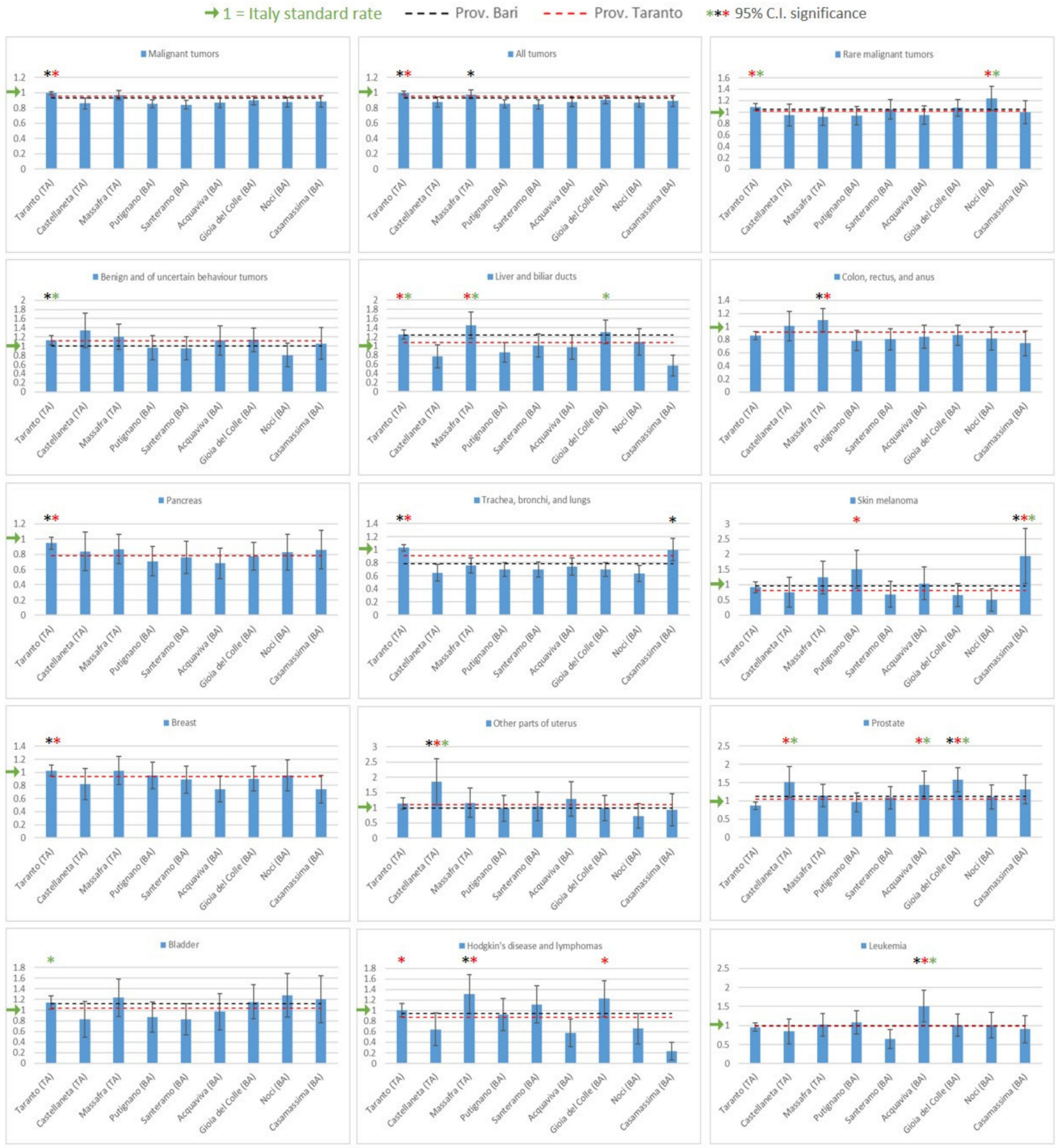

Figure 2. The 2009-2018 standardized mortality rate (SMR) in the population of the nine studied municipalities for specific types of tumours. Buffers indicate $95 \%$ C.I. The value of 1 (with a green arrow) is the national (Italy) standard. The dashed black and red lines show the mortality rate of the province of Bari and Taranto, respectively. The coloured asterisks * indicate that the municipality's SMR is statistically significant (above the 95\% C.I. lower bound) compared to the Italian (green asterisk) and provincial (Bari: black asterisk, and Taranto: red asterisk) rates. Rates for cancer types with no significance for any studied municipalities are not shown.

\section{Correlation between Standardized Mortality Rates and the Distance from the City of Taranto}

In an attempt to clarify the previous results, we also analysed the correlation between the standardized mortality rates for all specific cancer types in the decade 2009-2018 and 
the distance of all the nine municipalities from the industrial site of Taranto (Figure 3). The linear regression analysis of the mortality for 12 out of 15 tumour types shows a decreasing trend moving away from the city of Taranto (TA). The negative correlation between SMRs and distance from Taranto (TA) is strong $\left(R^{2}>0.30\right)$ for most of the specific cancers except for skin melanoma, prostate (the only tumour with a slightly positive correlation, $R^{2}=0.05$ ), and leukaemia. The increased mortality moving closer to the industrial site of Taranto is even stronger for all $\left(R^{2}=0.71\right)$ and malignant $\left(R^{2}=0.69\right)$ tumours, and colon, rectus and anus $\left(R^{2}=0.68\right)$, pancreas $\left(R^{2}=0.69\right)$, and breast $\left(R^{2}=0.67\right)$ cancers.

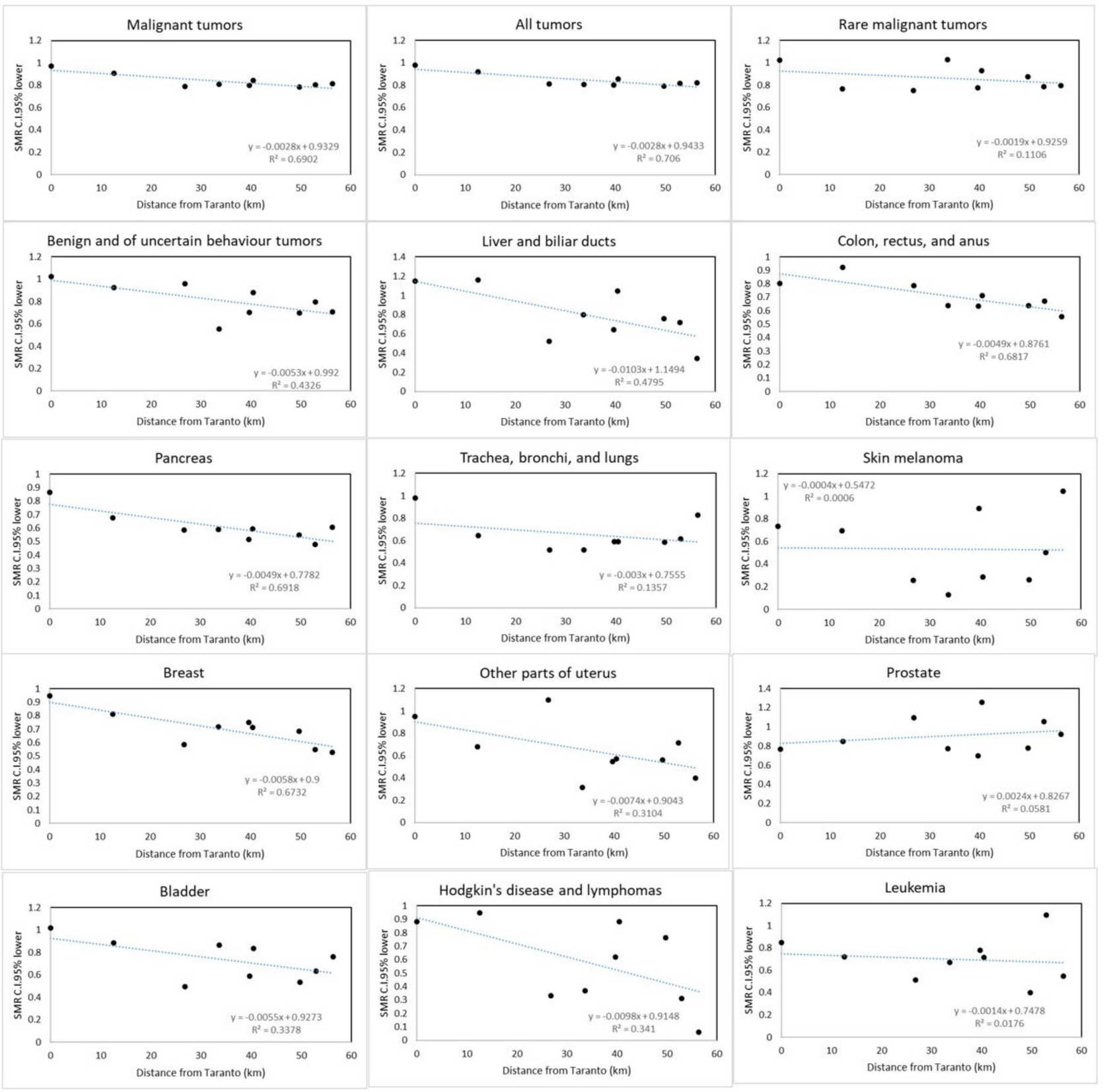

Figure 3. Correlation analysis of SMR (at 95\% lower C.I.) for each of the nine municipalities and their distance (in $\mathrm{km}$ ) from the industrial site of Taranto. Linear regression equations (slopes and intercepts) and Pearson's correlation coefficients (reported as coefficients of determination, $\mathrm{R}^{2}$ ) are shown in each plot. 


\section{Discussion}

According to the main cancer research institutes of the World Health Organization [20] and a recent wide revision of the scientific literature [21], in addition to a genetic component, often unknown, there are well-known environmental factors that increase the risk of developing certain types of tumours, such as ionizing radiation and exposure to chemicalindustrial substances, agricultural pesticides, and products derived from benzene.

Our results clearly show that the mortality for specific kinds of tumours in one of the most polluted Italian cities, the municipality of Taranto, is higher than the national standard and the provincial levels. Moreover, a detailed analysis revealed further interesting insights. The findings of this epidemiological study, in fact, dramatically confirm our hypothesis and provide strong evidence that the mortality rate for the majority (12 out of 15) of cancer types is higher among the residents of towns located closer to Taranto and is indirectly proportional (i.e., lower cancer mortality rate living farther from Taranto) with the distance from the industrial area of the city, one of the main source of pollution in the studied area.

Residents of Taranto show excessive mortality for 4 out of 15 cancer types (including high rates for rare, benign or with uncertain behaviour, and bladder cancer with liver tumour's mortality even higher than $15 \%$; Table 1). Although we have evidence that residents of our study sites who live closer to Taranto show higher rates for some specific cancer types, some excesses seem to not follow the correlation with the distance. This suggests that other local causes may be implicated in the excess of mortality, besides the potential dispersal of pollutants from the industrial area of Taranto at a downwind distance. For instance, Massafra (TA) - which is only $\sim 13 \mathrm{~km}$ linearly far from the industrial area of Taranto-shows an excess of mortality for liver tumours $(+16 \%)$, which is even higher than Taranto residents' level (Table 1). Castellaneta (TA)—which is just $14 \mathrm{~km}$ farther from Taranto on a linear distance-shows a $\sim 10 \%$ excesses for tumours of other parts of the uterus and prostate. Gioia del Colle (BA), even if located at $\sim 41 \mathrm{~km}$ from the industrial area of Taranto, also shows a quite high excess of liver tumour mortality $(+4.4 \%)$ and a very high rate of mortality for prostate cancers $(+25 \%)$. Similarly, Acquaviva delle Fonti (BA), distant $\sim 53 \mathrm{~km}$ from Taranto, shows mortality higher than the national standard for prostate $(+5 \%)$ and leukaemia $(+9 \%)$. Therefore, besides a few scattered excesses (such as for rare tumours in Noci (BA) and skin melanoma in Casamassima (BA)) among all municipalities, the epidemiological situation of Taranto (TA) appears dramatic, and that of Massafra (TA), Acquaviva delle Fonti (BA), and Gioia del Colle (BA) is just as serious. The residents of these four cities, in particular, show higher mortality rates for many cancer types not only over the national standard (which is inflated by the very high mortality rates of Northern Italian regions, particularly for residents of Padania Valley; [17]) but also compared to the mortality rates of the two provinces of Bari and Taranto to which they belong (Table 1).

From our results, we can, therefore, identify some common patterns. Cancers rates that are in excess in the city of Taranto are often also higher in the municipalities of closer cities. However, only Putignano (BA) and Santeramo (BA), among all study sites, shows low rates of cancer mortality for all of the specific tumour types. Besides the confirmation that some types of tumours are higher than the norm in the municipality of Taranto, it is noticeable that residents of Massafra (TA), Castellaneta (TA), Acquaviva delle Fonti (BA), and Gioia del Colle (BA) show higher tumour mortality rates that appear to be site-specific (particularly for liver, prostate, leukaemia and Hodgkin's syndrome).

The downwind position from Taranto's industrial area and the proximity to the industrial site of the city may explain most of the excesses of mortality for tumours found in this study. Nonetheless, there might be additional sources of pollution that could help explain high mortality rates for specific cancer types in the four towns above mentioned. For instance, many citizens of Massafra (TA) and Gioia del Colle (BA), in recent years, manifested apprehension regarding the possible dispersion of pollutants from the waste incinerator of Massafra (TA) $[22,23]$ and the experimentation plants on flameless and waste 
combustion (DISMO and CCA managed by ITEA and Ansaldo; [24]) located a few hundred meters from the residential zones in the two municipalities.

Table 1. Percent excess (lower C.I. 95\%) of mortality for the specific tumour types that exceed the national standard and types of tumours with mortality higher than the provincial levels in the studied municipalities (and their distance from the industrial site of Taranto).

\begin{tabular}{|c|c|c|c|c|}
\hline City & $\begin{array}{l}\text { Distance from the } \\
\text { Industrial Site }(\mathbf{k m})\end{array}$ & $\begin{array}{l}\text { \% Excess Mortality over } \\
\text { Italy Standard }\end{array}$ & $\begin{array}{c}\text { Tumours with } \\
\text { Mortality over Prov. } \\
\text { Bari Rate }\end{array}$ & $\begin{array}{l}\text { Tumours with } \\
\text { Mortality over Prov. } \\
\text { Taranto Rate }\end{array}$ \\
\hline Taranto (TA) & 0 & $\begin{array}{ll}- & \text { Rare }(+2.4 \%) \\
- & \text { Benign }(+2.5 \%) \\
- & \text { Liver }(+14.7 \%) \\
- & \text { Bladder }(+1.64 \%)\end{array}$ & $\begin{array}{ll}\text { - } & \text { Malignant } \\
\text { - } & \text { All tumours } \\
\text { - } & \text { Benign } \\
\text { - } & \text { Pancreas } \\
\text { - } & \text { Brachea, bronchi, lung }\end{array}$ & $\begin{array}{ll}\text { - } & \text { Malignant } \\
\text { - } & \text { All tumours } \\
\text { - } & \text { Rare } \\
\text { - } & \text { Liver and bile ducts } \\
\text { - } & \text { Trancreas } \\
& \text { lung } \\
\text { - } & \text { Skin melanoma } \\
\text { - } & \text { Breast } \\
\text { - } & \text { Hodgkin and } \\
& \text { lymphoma }\end{array}$ \\
\hline Castellaneta (TA) & 26.8 & $\begin{array}{ll}- & \text { Uterus }(+9.8 \%) \\
& \text { Prostate }(+9.7 \%)\end{array}$ & - Other parts of the uterus & $\begin{array}{ll}\text { - } & \text { Other parts of the } \\
\text { uterus } \\
\text { - } & \text { Prostate }\end{array}$ \\
\hline Massafra (TA) & 12.6 & - $\quad$ Liver $(+16 \%)$ & $\begin{array}{ll}\text { - } & \text { All tumours } \\
-\quad & \text { Colon, rectum, and anus } \\
\text { - } & \text { Hodgkin and lymphoma }\end{array}$ & $\begin{array}{l}\text { - } \quad \text { Liver and bile ducts } \\
\text { - } \quad \text { Colon, rectum, and } \\
\text { anus } \\
\text { - } \quad \text { Hodgkin and } \\
\text { lymphoma }\end{array}$ \\
\hline Putignano (BA) & 39.7 & & & - Skin melanoma \\
\hline Santeramo (BA) & 49.7 & & & \\
\hline $\begin{array}{l}\text { Acquaviva Delle } \\
\text { Fonti (BA) }\end{array}$ & 52.9 & $\begin{array}{ll}-\quad & \text { Prostate }(+5.4 \%) \\
-\quad & \text { Leukaemia }(+9.3 \%)\end{array}$ & - $\quad$ Leukaemia & $\begin{array}{ll}\text { - } & \text { Prostate } \\
\text { - } & \text { Leukaemia }\end{array}$ \\
\hline Gioia del Colle (BA) & 40.6 & $\begin{array}{ll}- & \text { Liver }(+4.4 \%) \\
- & \text { Prostate }(+25.4 \%)\end{array}$ & - $\quad$ Prostate & $\begin{array}{ll}- & \text { Prostate } \\
- & \text { Hodgkin and } \\
& \text { lymphoma }\end{array}$ \\
\hline Noci (BA) & 33.7 & - $\quad$ Rare $(+2.5 \%)$ & & - $\quad$ Rare $(+2.5 \%)$ \\
\hline Casamassima (BA) & 56.5 & - $\quad$ Skin $(+4.4 \%)$ & $\begin{array}{l}\text { - } \quad \text { Trachea, bronchi, lung } \\
\text { - } \quad \text { Skin melanoma }\end{array}$ & - $\quad$ Skin melanoma \\
\hline
\end{tabular}

The town of Massafra (TA), because of its proximity to Taranto, in the 90s was included in the "area at high risk of environmental crisis", as established by a decree of the Council of Italian Ministers [25]. Despite this, in 2003 the first plant for the production of electricity from fuel derived from waste incineration (CDR, a plant managed by Appia Energia Srl) came into operation. On 16 December 2013, the Regional Environmental Protection Agency (ARPA Puglia), in an information note sent to all the local administrative authorities, including the mayor of Massafra announced that the value of the maximum concentration of dioxins and PCBs exceeded in a sample of bovine milk collected from a farm located in the countryside of the town. Subsequent confirmatory analyses of additional milk samples showed an even more unfavourable outcome about PCDD/F and PCB contamination. The same regional agency (ARPA Puglia) in 2017 verified that the incinerator manager did not carry out any monitoring campaign for PM10, PM2.5, metals, and organic pollutants. Yet, during the inspection of soil samples (on agricultural land) a concentration of beryllium and vanadium above the threshold for metals, which are carcinogenic for human beings was found [26]. Then, ARPA reported that even the company's self-checks in 2014 and 2017 had shown an excess above the limits for beryllium and also for tin [26]. 
In Gioia del Colle (BA), experiments on waste treatment have been conducted for decades-during and before the period considered in this study-by ITEA and Ansaldo on a flameless plant called DISMO and on an incinerator plant called CCA, with the combustion of various types of waste, among which special and radioactive wastes [27].

In 2019 authorities acted a preventive seizure of the plant because of the "documented illegal disposal of dangerous waste containing carcinogenic and mutagenic of the maternal foetus chemical compounds, acid sludge, and residues of industrial chemical reactions" [28]. In addition, the extreme proximity to the inhabited centre of the city of Gioia del Colle of the "36th Storm" military airport, where radioactive weapons were stored [29], military radars are in operation, nuclear wastes deriving from the experiments carried out at the ITREC nuclear plant in Basilicata were delivered [30], and from which combat aircraft take off daily and can release huge quantities of exhaust gases that also contain carcinogens over the areas surrounding the town [31,32], has always caused great concern in the local population.

From analyses carried out by ARPA Puglia $[33,34]$ on the air quality of the urban centre of Gioia del Colle, in fact, indicative data concerning the toluene/benzene (T/B) ratio emerged. This ratio allows distinguishing the sources of chemical-industrial contamination from those of vehicular-road air pollution [35,36]. Values of this ratio above 4.5 and below 1.5 were detected in over $70 \%$ of the monitoring days in the municipal area, with high fluctuation in the sampling period, between December 2018 and June 2019 (i.e., with fluctuations recorded mainly on weekdays and seldom on holidays). These values could be indicative of an intermittent source of chemical-industrial pollution, such as a factory that works on alternate days (an experiment on waste incinerator?) or an airport operating mainly on selected working days (a military airport?). Toluene, in fact, is a relevant pollutant of factory productions [37] and a component of military jet fuels, as it can increase the octane number and, therefore, the power of the aircraft's engine [38]. Interestingly, the municipality of Castellaneta (TA) and Acquaviva delle Fonti (BA), with some mortality excesses even though free from industrial areas and waste incinerators, are downwind of Taranto, Massafra and Gioia del Colle.

Overall, mortality for less common tumours such as those of liver, bladder, and prostate is particularly high among the residents of Taranto, Massafra, Castellaneta, Acquaviva delle Fonti, and Gioia del Colle. Among the well-known environmental causes of liver and intrahepatic bile ducts tumours, there is exposure to fine particles PM2.5 [39], various industrial chemicals and ionizing radiation $[2,40]$. Furthermore, the high mortality from bladder tumours can be caused by pollution made of aromatic amines, compounds of industrial origin (which are released by combustion or by the treatment, for example, of tires, paints, and PVC) and pesticides, recognized environmental risk factors both for bladder and liver tumours [41-43]. There is also evidence that metal industries provide a significantly elevated risk for prostate cancer, but in the immediate vicinity, decaying with distance after about 10-15 km [44].

\section{Conclusions}

This study provides strong evidence on the relation between the distance from a heavy environmental pollution source and the rate of mortality for some tumour types: living closer to Taranto seems to increase the risk to die for cancer. However, the excess mortality among the residents of some specific municipalities (i.e., Massafra (TA), Castellaneta (TA), Acquaviva delle Fonti (BA), and Gioia del Colle (BA)) for liver, prostate, bladder, and blood cancers (leukaemia and Hodgkin's disease and lymphomas) suggests the presence, on the local territory (and not directly related to the industrial site of Taranto), of other significant sources of chemical-industrial and/or radioactive pollution such as to increase the rates concerning both the national level and that of the two provinces surveyed. This may represent a confirmation of the concerns about the presence of one or more, constant over time, sources of contamination located in the municipal areas.

Besides an immediate action to remove any form of heavy contamination deriving from the industrial site of Taranto, to shed more light on the problems that threat the envi- 
ronment and health and on the possible relationship between pollution and the incidence of some serious proliferative diseases affecting the citizens of some surrounding towns, we recommend detailed medical and air quality monitoring (with analysis of chemical-industrial atmospheric pollutants such as IPA, Dioxins, PCBs, PM2.5, etc. and electromagnetic pollution), water (with analysis of the presence of heavy metals and radioactivity in drinking water) and soil (with analysis of chemical contaminants, pesticides, PAHs, PCBs, dioxins, heavy metals, etc. and radioactivity in soil and local food products).

In conclusion, we found that dispersion of air pollutants from the industrial area of Taranto may contaminate the surrounding environment, extend over kilometres of distance, and damage the health of people, particularly those living in closer towns, increasing their risk of mortality for some specific tumours. However, we also discovered that some specific types of cancer have an uneven distribution in the provinces of Taranto and Bari. The proximity to the industrial area of Taranto cannot, therefore, explain all the anomalies detected in some populations (particularly those of Acquaviva delle Fonti, Gioia del Colle, Castellaneta, and Massafra). Likely, other site-specific sources of heavy pollution (not only related to air pollutants, which was used in this study just as a proxy of the whole environmental contamination that can also derive from soil and water) are playing a role in worsening the death toll of these towns and this must be taken into serious consideration by environmental policymakers and local authorities.

Author Contributions: R.C.G. conceived the idea, analysed the data and wrote the manuscript. A.V. collected the data and support the analysis of them. R.C.G. and A.V. prepared figures and graphical material. All authors have read and agreed to the published version of the manuscript.

Funding: This research received no external funding.

Informed Consent Statement: Not applicable.

Data Availability Statement: Data used in this study are publicly available at the sources cited in the methods.

Conflicts of Interest: The authors declare no actual or potential competing financial interests.

\section{References}

1. Fajersztajn, L.; Veras, M.; Barrozo, L.V.; Saldiva, P. Air pollution: A potentially modifiable risk factor for lung cancer. Nat. Rev. Cancer 2013, 13, 674-678. [CrossRef] [PubMed]

2. Sanli, O.; Dobruch, J.; Knowles, M.A.; Burger, M.; Alemozaffar, M.; Nielsen, M.E.; Lotan, Y. Bladder cancer. Nat. Rev. Dis. Prim. 2017, 3, 17022. [CrossRef] [PubMed]

3. Letašiová, S.; Medved'ová, A.; Šovčíková, A.; Dušinská, M.; Volkovová, K.; Mosoiu, C.; Bartonová, A. Bladder cancer, a review of the environmental risk factors. Environ. Health 2012, 11 (Suppl. 1), S11. [CrossRef] [PubMed]

4. Lelieveld, J.; Evans, J.S.; Fnais, M.; Giannadaki, D.; Pozzer, A. The contribution of outdoor air pollution sources to premature mortality on a global scale. Nature 2015, 525, 367-371. [CrossRef]

5. Pirastu, R.; Comba, P.; Iavarone, I.; Zona, A.; Conti, S.; Minelli, G.; Manno, V.; Mincuzzi, A.; Minerba, S.; Forastiere, F.; et al. Environment and Health in Contaminated Sites: The Case of Taranto, Italy. J. Environ. Public Health 2013, 2013, 753719. [CrossRef]

6. Greco, L.; Di Fabbio, M. Path-dependence and change in an old industrial area: The case of Taranto, Italy. Camb. J. Reg. Econ. Soc. 2014, 7, 413-431. [CrossRef]

7. Mangia, C.; Gianicolo, E.A.L.; Bruni, A.; Vigotti, M.A.; Cervino, M. Spatial variability of air pollutants in the city of Taranto, Italy and its potential impact on exposure assessment. Environ. Monit. Assess. 2012, 185, 1719-1735. [CrossRef]

8. Marinaccio, A.; Belli, S.; Binazzi, A.; Scarselli, A.; Massari, S.; Bruni, A.; Conversano, M.; Crosignani, P.; Minerba, A.; Zona, A.; et al. Residential proximity to industrial sites in the area of Taranto (Southern Italy). A case-control cancer incidence study. Ann. Dell'istituto Super. Sanità 2011, 47, 192-199.

9. Vigotti, M.A.; Mataloni, F.; Bruni, A.; Minniti, C.; Gianicolo, E.A.L. Mortality analysis by neighbourhood in a city with high levels of industrial air pollution. Int. J. Public Heath 2014, 59, 645-653. [CrossRef]

10. Pirastu, R.; Comba, P.; Conti, S.; Iavarone, I.; Fazzo, L.; Pasetto, R.; Zona, A.; Crocetti, E.; Ricci, P. Gruppo di lavoro SENTIERIMortalità, incidenza oncologica e ricoveri ospedalieri nei Siti di Interesse Nazionale per le bonifiche. (A cura di). SENTIERI-Studio epidemiologico nazionale dei territori e degli insediamenti esposti a rischio da inquinamento: Mortalità, incidenza oncologica e ricoveri ospedalieri. Epidemiol. Prev. 2018, 38, 1-170.

11. Bianco, G.; Zianni, R.; Anzillotta, G.; Palma, A.; Vitacco, V.; Scrano, L.; Cataldi, T.R. Dibenzo-p-dioxins and dibenzofurans in human breast milk collected in the area of Taranto (Southern Italy): First case study. Anal. Bioanal. Chem. 2013, 405, 2405-2410. 
12. Martinelli, D.; Mincuzzi, A.; Minerba, S.; Tafuri, S.; Conversano, M.; Caputi, G.; Lopalco, P.L.; Quarto, M.; Germinario, C.A.; Prato, R. Malignant cancer mortality in Province of Taranto (Italy). Geographic analysis in an area of high environmental risk. J. Prev. Med. Hyg. 2009, 50, 181-190.

13. Tateo, A.; Miglietta, M.M.; Fedele, F.; Menegotto, M.; Pollice, A.; Bellotti, R. A statistical method based on the ensemble probability density function for the prediction of "Wind Days". Atmos. Res. 2019, 216, 106-116. [CrossRef]

14. Levy, I.; Dayan, U.; Mahrer, Y. A five-year study of coastal recirculation and its effect on air pollutants over the East Mediterranean region. J. Geophys. Res. Earth Surf. 2008, 113, D16.

15. Gangoiti, G.; Millán, M.M.; Salvador, R.; Mantilla, E. Long-range transport and re-circulation of pollutants in the western Mediterranean during the project Regional Cycles of Air Pollution in the West-Central Mediterranean Area. Atmos. Environ. 2001, 35, 6267-6276. [CrossRef]

16. Laiola, E.; Giungato, P. Wind characterization in Taranto city as a basis for innovative sustainable urban development. J. Clean. Prod. 2018, 172, 3535-3545.

17. ISTAT. 2020. Available online: http:/ / dati.istat.it/?lang=en (accessed on 11 September 2019).

18. R Core Team. R: A Language and Environment for Statistical Computing; R Foundation for Statistical Computing: Vienna, Austria, 2019; Available online: https:/ / www.R-project.org/ (accessed on 10 May 2018).

19. Pickle, L.W.; White, A.A. Effects of the choice of age-adjustment method on maps of death rates. Stat. Med. 1995, 14, 615-627.

20. International Agency for Research on Cancer; World Health Organization. IARC: Outdoor Air Pollution a Leading Environmental Cause of Cancer Deaths; WHO, 221; International Agency for Research on Cancer: Lyon, France, 2013.

21. Cazzolla Gatti, R. Why we will continue to lose our battle with cancers if we do not stop their triggers from environmental pollution. Int. J. Environ. Res. Public Health 2021, 18, 6107.

22. Little, M.P. Risks associated with ionizing radiation: Environmental pollution and health. Br. Med. Bull. 2013, 68, $259-275$.

23. Valerio, F. Environmental impacts of post-consumer material managements: Recycling, biological treatments, incineration. Waste Manag. 2010, 30, 2354-2361.

24. Presciutti, A.; Asdrubali, F.; Baldinelli, G.; Rotili, A.; Malavasi, M.; Di Salvia, G. Energy and exergy analysis of glycerol combustion in an innovative flameless power plant. J. Clean. Prod. 2018, 172, 3817-3824. [CrossRef]

25. Council of the Italian Ministries. 1998. Available online: https://www.gazzettaufficiale.it/eli/id/1998/11/30/98A10155/sg (accessed on 24 September 2020).

26. ISDE Medici. Extremes and Lies about Waste Incineration in Massafra. Terre di Frontiera. 2018. Available online: https: //www.terredifrontiera.info/sforamenti-appia-energy-massafra/ (accessed on 11 September 2019).

27. Regione Puglia. Bollettino Ufficiale della Regione Puglia, n. 42. 6 April 2017. Available online: https:/ / burp.regione.puglia.it/ documents /20135/1049418/Bollettino+numero+42+-+Ordinario+-+anno+2017.pdf/6d539daf-57cb-aaab-88d6-dd810e6bae65? $\mathrm{t}=1622808496772$ (accessed on 11 September 2019).

28. Consiglio Regionale della Puglia. Gioia del Colle, Sequestration of the Oxy-Combustion System. M5S: "Ensuring Adequate Controls for the Experimentation of Innovative Technologies". 2019. Available online: https://www.consiglio.puglia.it/-/ gioia-del-colle-sequestro-impianto-ossicombustione.-m5s-assicurare-controlli-adeguati-per-la-sperimentazione-di-tecnologieinnovative-1 (accessed on 11 September 2019).

29. Verbeek, B.; Giacomello, G. Italy's Foreign Policy in the Twenty-First Century: The New Assertiveness of an Aspiring Middle Power; Lexington Books: Minneapolis, MN, USA, 2011.

30. VICE. 2016. Available online: https://www.vice.com/it/article/d3q3by/elk-river-italia-usa-nucleare (accessed on 11 September 2019).

31. Ruijgrok, G.J.; Van Paassen, D.M. Elements of Aircraft Pollution; Delft University Press: Delft, The Netherlands, 2005.

32. Yim, S.H.L.; Lee, G.L.; Lee, I.H.; Allroggen, F.; Ashok, A.; Caiazzo, F.; Eastham, S.D.; Malina, R.; Barrett, S.R.H. Global, regional and local health impacts of civil aviation emissions. Environ. Res. Lett. 2015, 10, 34001. [CrossRef]

33. ARPA Puglia. Prima Campagna di Monitoraggio della Qualita dell'Aria con Laboratorio Mobile. Available online: https: //www.arpa.puglia.it/moduli/output_immagine.php?id=5096 (accessed on 11 September 2019).

34. ARPA Puglia. Seconda Campagna di Monitoraggio della Qualita dell'Aria con Laboratorio Mobile. Available online: https: / / www.arpa.puglia.it/moduli/output_immagine.php?id=5097 (accessed on 26 November 2019).

35. Gelencsér, A.; Siszler, K.; Hlavay, J. Toluene-benzene concentration ratio as a tool for characterizing the distance from vehicular emission sources. Environ. Sci. Technol. 1997, 31, 2869-2872. [CrossRef]

36. Miller, L.; Xu, X.; Grgicak-Mannion, A.; Brook, J.; Wheeler, A. Multi-season, multi-year concentrations and correlations amongst the BTEX group of VOCs in an urbanized industrial city. Atmos. Environ. 2012, 61, 305-315. [CrossRef]

37. Hofstetter, T.B.; Capello, C.; Hungerbühler, K. Environmentally preferable treatment options for industrial waste solvent management: A case study of a toluene containing waste solvent. Process Saf. Environ. 2003, 81, 189-202. [CrossRef]

38. Humer, S.; Frassoldati, A.; Granata, S.; Faravelli, T.; Ranzi, E.; Seiser, R.; Seshadri, K. Experimental and kinetic modeling study of combustion of JP-8, its surrogates and reference components in laminar nonpremixed flows. Proc. Combust. Inst. 2007, 31, 393-400. [CrossRef]

39. Deng, H.; Eckel, S.P.; Liu, L.; Lurmann, F.W.; Cockburn, M.G.; Gilliland, F.D. Particulate matter air pollution and liver cancer survival. Int. J. Cancer 2017, 141, 744-749. [CrossRef]

40. Santella, R.M.; Wu, H.-C. Environmental Exposures and Hepatocellular Carcinoma. J. Clin. Transl. Hepatol. 2016, 1, 138-143. 
41. Webster, L.R.; McKenzie, G.H.; Moriarty, H.T. Organophosphate-based pesticides and genetic damage implicated in bladder cancer. Cancer Genet. Cytogenet. 2002, 133, 112-117. [CrossRef]

42. Talaska, G. Aromatic Amines and Human Urinary Bladder Cancer: Exposure Sources and Epidemiology. J. Environ. Sci. Health Part C 2003, 21, 29-43. [CrossRef]

43. De Vocht, F.; Sobala, W.; Wilczynska, U.; Kromhout, H.; Szeszenia-Dabrowska, N.; Peplonska, B. Cancer mortality and occupational exposure to aromatic amines and inhalable aerosols in rubber tire manufacturing in Poland. Cancer Epidemiol. 2009, 33, 94-102. [CrossRef]

44. Ramis, R.; Diggle, P.; Cambra, K.; López-Abente, G. Prostate cancer and industrial pollution: Risk around putative focus in a multi-source scenario. Environ. Int. 2011, 37, 577-585. [CrossRef] 